\title{
PENGARUH PEMBELAJARAN KOOPERATIF MODEL STAD TERHADAP MATA PELAJARAN PKN KELAS V SDN SEDAPURKLAGEN TAHUN PELAJARAN 2016/2017
}

\author{
Kasun \\ SDN Sedapurklagen Gresik \\ kasun@gmail.com
}

\begin{abstract}
ABSTRAK
Bagaimanakah caranya agar siswa tidak melupakan materi pelajaran yang telah diterimanya agar siswa nantinya siap menghadapi ujian kenaikan kelas yang siap atau tidak siap harus mereka hadapi. Bagaimanakah membuat suatu materi ajar agar agar tidak terlupakan oleh anak didik. Dalam hal ini guru harus mencari metode untuk mengingatkan segala memori di benak siswa yang telah mereka terima. Guru harus bisa membangkitkan kembali memori itu. Penelitian ini menggunakan penelitian tindakan (action research) sebanyak tiga putaran. Setiap putaran terdiri dari empat tahap yaitu: rancangan, kegiatan dan pengamatan, refleksi, dan refisi. Sasaran penelitian ini adalah siswa kelas V di SDN Sedapurklagen tahun pelajaran 2016/2017 Data yang diperoleh berupa hasil tes formatif, lembar observasi kegiatan belajar mengajar. Dari hasil analis didapatkan bahwa prestasi belajar siswa mengalami peningkatan dari siklus I sampai siklus III yaitu, siklus I (72,43\%), siklus II (78,32\%), siklus III (89,18\%). Kesimpulan dari penelitian ini adalah metode Pembelajaran Kooperatif Model STAD pada materi pelajaran PKN dapat berpengaruh positif terhadap motivasi belajar Siswa kelas $\mathrm{V}$ serta Pembelajaran Kooperatif Model STAD ini dapat digunakan sebagai salah satu alternatif pembelajaran.
\end{abstract}

Kata Kunci: Metode Pembelajaran Kooperatif, STAD.

\section{ABSTRACT}

How can students not forget the lesson material they have received so that students will be ready to face upgrading tests that are ready or not ready to face. How to make a teaching material so as not to be forgotten by the students. In this case the teacher should look for methods to remind all the memory in the minds of students they have received. The teacher must be able to revive the memory. This research uses action research for three rounds. Each round consists of four stages: design, activity and observation, reflection, and refission. Target of this research is class V student at SDN Sedapurklagen year lesson 2016/2017 Data obtained in formative test result, observation sheet of teaching and learning activity. From the analyst's result, it is found that the students' learning achievement has improved from cycle I to cycle III that is, cycle I (72,43\%), cycle II (78,32\%), cycle III $(89,18 \%)$. The conclusion of this research is the method of Cooperative Learning Model STAD on PKN subject matter can have a positive effect on learning motivation Grade V students and Cooperative Learning STAD model can be used as an alternative learning.

Keywords: Cooperative Learning Method, STAD.

\section{PENDAHULUAN}

Pada abad 21 ini, kita perlu menelaah kembali praktik-praktik pembelajaran di sekolah-sekolah. Peranan yang harus dimainkan oleh dunia pendidikan dalam mempersiapkan anak didik untuk berpartisipasi secara utuh dalam kehidupan bermasyarakat di abad 21 akan sangat berbeda dengan peranan tradisional yang selama ini dipegang oleh sekolah-sekolah. 
Ada persepsi umum yang sudah berakar dalam dunia pendidikan dan juga sudah menjadi harapan masyarakat. Persepsi umum ini menganggap bahwa sudah merupakan tugas guru untuk mengajar dan menyodori siswa dengan muatan-muatan informasi dan pengetahuan. Guru perlu bersikap atau setidaknya dipandang oleh siswa sebagai yang mahatahu dan sumber informasi. Lebih celaka lagi, siswa belajar dalam situasi yang membebani dan menakutkan karena dibayangi oleh tuntutan-tuntutan mengejar nilai-nilai tes dan ujian yang tinggi.

Tampaknya, perlu adanya perubahan paradigma dalam menelaah proses belajar siswa dan interaksi antara siswa dan guru. Sudah seyogyanyalah kegiatan belajar mengajar juga lebih mempertimbangkan siswa. Siswa bukanlah sebuah botol kosong yang bisa diisi dengan muatan-muatan informasi apa saja yang dianggap perlu oleh guru. Selain itu, alur proses belajar tidak harus berasal dari guru menuju siswa. Siswa bisa juga saling mengajar dengan sesama siswa yang lainnnya. Bahkan, banyak penelitian menunjukkan bahwa pengajaran oleh rekan sebaya (peer teaching) ternyata lebih efektif daripada pengajaran oleh guru. Sistem pengajaran yang memberi kesempatan kepada anak didik untuk bekerjasama dengan sesama siswa dalam tugas-tugas yang terstruktur disebut sebagai sistem "pembelajaran gotong royong" atau cooperative learning. Dalam sistem ini, guru bertindak sebagai fasilitator.

Ada beberapa alasan penting mengapa sistem pengajaran ini perlu dipakai lebih sering di sekolahsekolah. Seiring dengan proses globalisasi, juga terjadi transformasi sosial, ekonomi, dan demografis yang mengharuskan sekolah untuk lebih menyiapkan anak didik dengan keterampilan-keterampilan baru untuk bisa ikut berpartisipasi dalam dunia yang berubah dan berkembang pesat.

Sesungguhnya, bagi guru-guru di negeri ini metode gotong royong tidak terlampau asing dan mereka telah sering menggunakannya dan mengenalnya sebagai metode kerja kelompok. Memang tidak bisa disangkal bahwa banyak guru telah sering menugaskan para siswa untuk bekerja dalam kelompok.

Sayangnya, metode kerja kelompok sering dianggap kurang efektif. Berbagai sikap dan kesan negatif memang bermunculan dalam pelaksaan metode kooperatif model STAD. Jika kerja kelompok tidak berhasil, siswa cenderung saling menyalahkan. Sebaliknya jika berhasil, muncul perasaan tidak adil. Siswa yang pandai/rajin merasa rekannya yang kurang mampu telah membonceng pada hasil kerja mereka. Akibatnya, metode kerja kelompok yang seharusnya bertujuan mulia, yakni menanamkan rasa 
persaudaraan dan kemampuan bekerja sama, justru bisa berakhir dengan ketidakpuasaan dan kekecewaaan. Bukan hanya guru dan siswa yang merasa pesimis mengenai penggunaan metode kerja kelompok, bahkan kadang-kadang orang tua pun merasa was-was jika anak mereka dimasukkan dalam satu kelompok dengan siswa lain yang dianggap kurang seimbang.

Berbagai dampak negatif dalam menggunakan metode kerja kelmpok tersebut seharusnya bisa dihindari jika saja guru mau meluangkan lebih banyak waktu dan perhatian dalam mempersiapkan dan menyusun metode kerja kelompok. Yang diperkanalkan dalam metode pembelajaran cooperative learning bukan sekedar kerja kelompok, melainkan pada penstrukturannya. Jadi, sistem pengajaran cooperative learning bisa didefinisikan sebagai kerja/belajar kelompok yang terstruktur. Yang termasuk di dalam struktur ini adalah lima unsure pokok (Johnson \& Johnson, 1993), yaitu saling ketergantungan positif, tanggung jawab individual, interaksi personal, keahlian bekerja sama, dan proses kelompok.

Kekawatiran bahwa semangat siswa dalam mengembangkan diri secara individual bisa terancam dalam penggunaan metode kerja kelompok bisa dimengerti karena dalam penugasan kelompok yang dilakukan secara sembarangan, siswa bukannya belajar secara maksimal, melainkan belajar mendominasi ataupun melempar tanggung jawab. Metode pembelajaran gotong royong distruktur sedemikian rupa sehingga masing-masing anggota dalam satu kelompok melaksanakan taanggung jawab pribadinya karena ada sistem akuntabilitas individu. Siswa tidak bisa begitu saja membonceng jerih payah rekannya dan usaha setiap siswa akan dihargai sesuai dengan poin-poin perbaikannya.

Dari latar belakang masalah tersebut, maka peneliti merasa terdorong untuk melihat pengaruh pembelajaran terstruktur dan pemberian balikan terhadap prestasi belajar siswa dengan mengambil judul Pengaruh Pembelajaran Kooperatif Model STAD Terhadap Mata Pelajaran PKN Kelas V SDN Sedapurklagen Kecamatan Benjeng Kabupaten Gresik Tahun Pelajaran 2016/2017

\section{METODOLOGI PENELITIAN}

Subjek dalam penelitian ini adalah siswa kelas $V$ SDN Sedapurklagen Kecamatan Benjeng Kabupaten Gresik Tahun Pelajaran 2016/2017. Penelitian ini dilakukan dalam dua siklus dengan setiap siklusnya terdiri dari tahap-tahap sebagai berikut :

\section{SIKLUS I}

a) Perencanaan

Setelah melaksanakan pembelajaran ternyata dari 31 siswa hanya 4 yang paham dalam pembelajaran PKN Menurut 


\begin{abstract}
pengamatan teman sejawat ternyata penyebab siswa kurang paham dikarenakan waktu menjelaskan guru tidak mengaitkan dengan kehidupan sehari-hari. Sehingga siswa tidak tertarik untuk mengikuti pembelajaran. Maka dari itu untuk meningkatkan motivasi belajar siswa kelas V SDN Sedapurklagen Kecamatan Benjeng Kabupaten Gresik Tahun Pelajaran 2016/2017 peneliti mengadakan rencana perbaikan yang dilengkapi dengan alat-alat dan metode yang sesui dengan pembelajaran.
\end{abstract}

b) Pelaksanaan

1) Kegiatan Awal

- Memotivasi siswa agar terdorong untuk mempelajari lebih jauh tentang PKN

2) Kegiatan Inti

- Mengaitkan materi dengan kehidupan sehari-hari

- Membimbing siswa untuk mengamati gambar

- Membimbing siswa untuk melakukan diskusi dan kerja kelompok

- Mengarahkan siswa untuk membacakan hasil diskusinya

3) Kegiatan Akhir

- Tanya jawab materi

c) Pengumpulan data

Setelah pembelajaran siklus I dilaksanakan, data dan informasi pendukung yang terkumpul sebagai berikut:
- Hasil evaluasi dari 31 siswa hanya 17 siswa yang memperoleh nilai kurang dari 70, dengan demikian keenam siswa ini dapat dikategorikan kurang memahami materi

- Menurut hasil pengamatan yang dilakukan teman sejawat terhadap pelaksanaan pembelajaran siklus I adalah penggunaan media gambar sudah tepat namun pengunaan media lain serta metode pembelajaran yang sesuai dengan materi perlu digunakan.

d) Refleksi (Analisis dan Interpretasi)

- Pengetahuaan siswa dalam memahami materi yang dipelajari menigkat daripada sebelum melaksanakan penelitian ini.

- Prestasi belajar siswa siklus rata-rata 65,20\%.

- Rencana yang telah dibuat dapat bermanfaat dan berjalan dengan lancar

\section{SIKLUS II}

e) Perencanaan

Pada pelaksanaan perbaikan pembelajaran siklus I sudah mengalami kemajuan, dari 31 siswa hanya 3 siswa yang kurang memahami materi. Maka dari itu direncanakan pembelajaran siklus II dengan penekanan guru lebih sering memberikan penjelasan 
dan pertanyaan yang dikaitkan dengan kehidupan sehari-hari siswa serta memakai metode yang tepat dan sesuai dengan materi pembelajaran yang ada dengan harapan kemampuan siswa pada pembelajaran PKN. Pelaksanaannya adalah sebagai berikut:

1) Kegiatan Awal

- Memotivasi siswa agar terdorong untuk mempelajari lebih jauh tentang PKN

2) Kegiatan Inti

- Mengaitkan materi dengan kehidupan sehari-hari

- Membimbing siswa untuk menceritakan tentang PKN

- Membimbing siswa untuk melakukan diskusi tentang materi dan mengarahkan siswa dalam diskusi tersebut

3) Kegiatan Akhir

- Tanya jawab tentang materi

f) Pengumpulan data

Dari hasil evaluasi dan observasi teman sejawat terhadap pelaksanaan pembelajaran siklus II, dari 31 siswa hanya 3 siswa yang kurang paham.ini terbukti dari hasil tes siklus II kedua .siswa tersebut mendapat nilai kurang dari 70.

g) Refleksi (Analisis dan Interpretasi)

Pembelajaran siklus II siswa sudah 78,60 \% memahami materi. Ternyata dengan media pembelajaran serta ditunjang dengan metode yang sesuai dengan materi tersebut dan mengaitkannya dengan kehidupan sehari-hari pemahaman siswa menjadi meningkat.

HASIL PENELITIAN DAN PEMBAHASAN

Penelitian Tindakan Kelas ini dilaksanakan sebanyak dua siklus dengan rincian sebagai berikut.

\section{Siklus I}

1. Perencanaan

Peneliti menyiapkan : Rencana Pembelajaran, Alat Peraga, Lembar Kerja, Lembar Pengamatan Guru, Lembar Evaluasi, dan Lembar Pengamatam Siswa.

2. Pelaksanaan

- Melaksanakan kegiatan pembelajaran sesuai dengan langkahlangkah yang telah direncanakan.

- Melaksanakan penelitian

Dalam melaksanakan siklus I, guru mengadakan perjanjian dengan teman sejawat untuk membantunya mengamati situasi di dalam kelas pada proses pembelajaran dalam rangka memperbaiki cara mengajar.

3. Pengumpulan Data

Pada saat melaksanakan proses pembelajaran, teman sejawat melakukan pengamatan dengan menggunakan instrument yaitu lembar pengamatan guru, dan lembar pengamatan siswa. Kemudian pada saat kegiatan pembelajaran berakhir guru 
mengadakan penilaian akhir terhadap mata pelajaran PKN.

Data-data di atas akan digunakan sebagai sumber untuk menentukan kesimpulan. Lebih jelasnya, dapat dilihat pada tabeltabel berikut:

Tabel 1. Hasil pengamatan kegiatan siswa siklus I

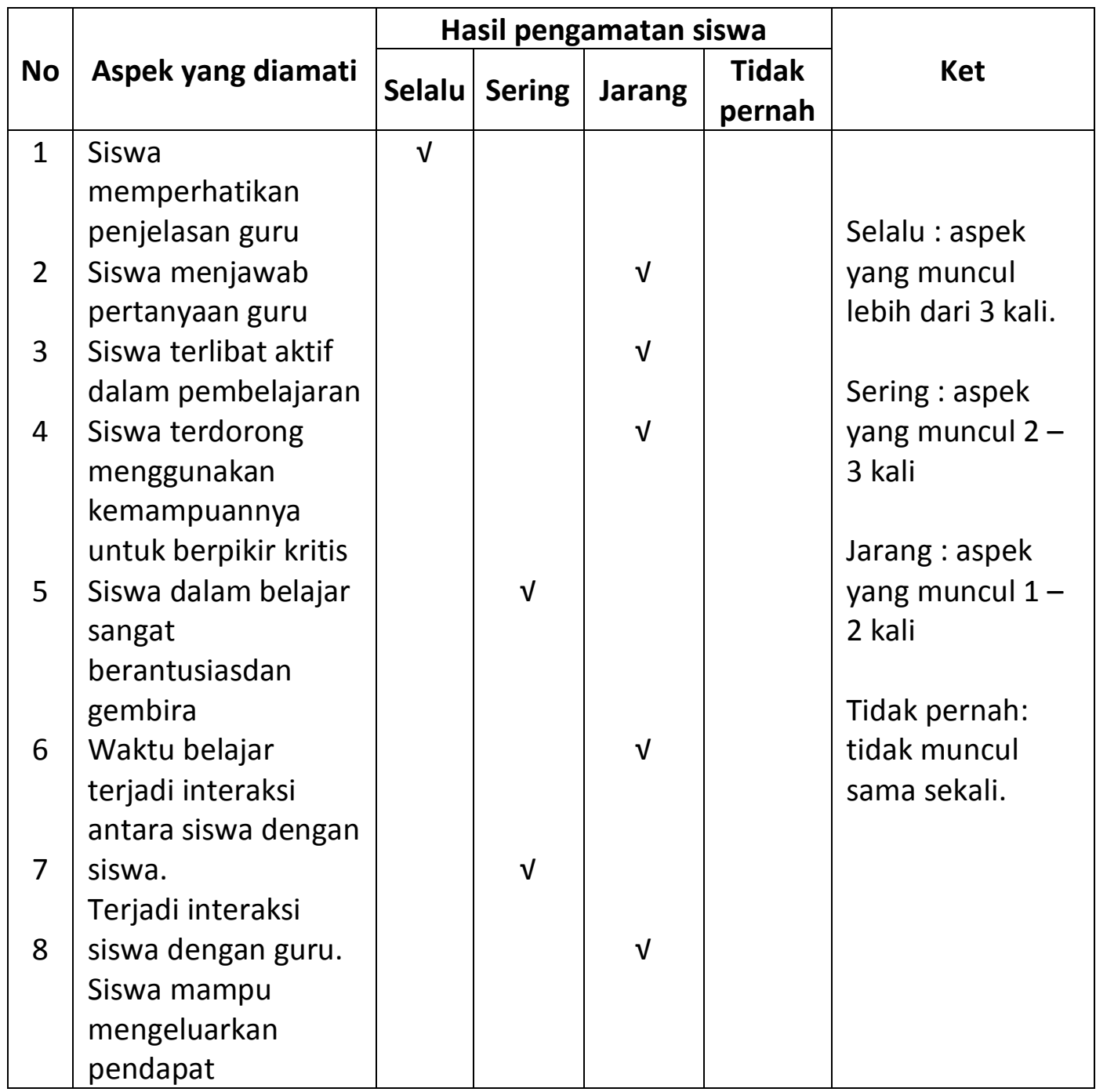

Tabel 2. Hasil pengamatan Kegiatan guru pada siklus I

\begin{tabular}{|c|c|c|c|c|c|c|}
\hline \multirow[b]{2}{*}{ No } & \multirow[b]{2}{*}{$\begin{array}{l}\text { Aspek yang } \\
\text { diamati }\end{array}$} & \multicolumn{4}{|c|}{ Hasil pengamatan } & \multirow[b]{2}{*}{ Ket } \\
\hline & & Selalu & Sering & Jarang & $\begin{array}{l}\text { Tidak } \\
\text { pernah }\end{array}$ & \\
\hline$A$ & Kegiatan awal & & & & & \\
\hline 1 & Membangkitkan & & V & & & \\
\hline 2 & $\begin{array}{l}\text { Mengkomunikasik } \\
\text { an tujuan } \\
\text { pembelajaran }\end{array}$ & $V$ & & & & $\begin{array}{l}\text { yang muncul } \\
\text { lebih dari } 3 \text { kali }\end{array}$ \\
\hline
\end{tabular}




\begin{tabular}{|c|c|c|c|c|c|c|}
\hline \multirow[b]{2}{*}{ No } & \multirow{2}{*}{$\begin{array}{c}\text { Aspek yang } \\
\text { diamati }\end{array}$} & \multicolumn{4}{|c|}{ Hasil pengamatan } & \multirow[b]{2}{*}{ Ket } \\
\hline & & Selalu & Sering & Jarang & $\begin{array}{c}\text { Tidak } \\
\text { pernah }\end{array}$ & \\
\hline$B$ & Kegiatan inti & & \multirow{6}{*}{ V } & & & \multirow{9}{*}{$\begin{array}{l}\text { Sering : aspek } \\
\text { yang muncul } 2 \\
-3 \text { kali } \\
\text { Jarang : aspek } \\
\text { yang muncul } 1 \\
-2 \text { kali } \\
\text { Tidak pernah : } \\
\text { tidak muncul } \\
\text { sama sekali. }\end{array}$} \\
\hline 1 & $\begin{array}{l}\text { Mengaitkan } \\
\text { masalah } \\
\text { dengan kehidupan } \\
\text { sehari-hari. }\end{array}$ & & & & & \\
\hline 2 & $\begin{array}{l}\text { Menggunakan alat } \\
\text { peraga yang } \\
\text { sesuai. }\end{array}$ & & & V & & \\
\hline 3 & $\begin{array}{l}\text { Membimbing dan } \\
\text { memperhatikan } \\
\text { siswa. }\end{array}$ & & & v & & \\
\hline 4 & $\begin{array}{l}\text { Memancing siswa } \\
\text { untuk } \\
\text { mengemukakan } \\
\text { pendapatnya. }\end{array}$ & & & v & & \\
\hline 5 & $\begin{array}{l}\text { Menghargai } \\
\text { pendapat siswa } \\
\text { dan memberi } \\
\text { penghargaan. }\end{array}$ & & & V & & \\
\hline$C$ & Kegiatan akhir & & & & & \\
\hline 1 & $\begin{array}{l}\text { Membuat } \\
\text { simpulan }\end{array}$ & & V & & & \\
\hline 2 & $\begin{array}{l}\text { Melakukan } \\
\text { penilaian. }\end{array}$ & v & & & & \\
\hline
\end{tabular}

Analisis :

Berdasarkan hasil diskusi dengan teman sejawat, perbaikan pembelajaran siklus I bahwa dapat dilihat hasil belajar siswa kelas $\mathrm{V}$ rata-rata $65,20 \%$.

\section{Refleksi}

Pada siklus I dapat dikatakan bahwa hasil rata-rata ulangan siswa $\mathrm{V}$ masih kurang dan dibawah standart yang telah ditetapkan oleh guru hal itu karena strategi yang diterapkan oleh guru kurang berhasil dan perlu sekali peningkatan
Siklus II

1. Perencanaan

Peneliti menyiapkan peralatan yang diperlukan yaitu:

- Rencana Perbaikan Pembelajaran

- Alat Peraga yang diperlukan

- Lembar Kerja Siswa

- Lembar Kelengkapan Pengamatan

2. Pelaksanaan

- Melaksanakan proses pembelajaran sesuai dengan langkah-langkah yang telah dibuat pada RPP II 
- Lebih

pembelajaran

menggunakan

menekankan

dengan

metode

Pembelajaran Kooperatif Model

STAD

- Melaksanakan penilaian

3. Pengamatan / pengumpulan data
- Pada saat melaksanakan kegiatan pembelajaran siklus II ini kami memperoleh data yang berasal dari hasil pengamatan kegiatan guru, kegiatan siswa dan hasil nilai evaluasi siswa. Data-data tersebut digunakan sebagai dasar pengamatan

Tabel 3. Hasil pengamatan kegiatan siswa siklus I

\begin{tabular}{|c|c|c|c|c|c|c|}
\hline \multirow[b]{2}{*}{ No } & \multirow[b]{2}{*}{ Aspek yang diamati } & \multicolumn{4}{|c|}{ Hasil pengamatan siswa } & \multirow[b]{2}{*}{ Ket } \\
\hline & & Selalu & Sering & Jarang & $\begin{array}{c}\text { Tidak } \\
\text { pernah }\end{array}$ & \\
\hline 1 & $\begin{array}{l}\text { Siswa } \\
\text { memperhatikan } \\
\text { penjelasan guru }\end{array}$ & $\sqrt{ }$ & & & & $\begin{array}{l}\text { Selalu : aspek } \\
\text { yang muncul } \\
\text { lebih dari } 3 \text { kali. }\end{array}$ \\
\hline 2 & $\begin{array}{l}\text { Siswa menjawab } \\
\text { pertanyaan guru }\end{array}$ & $\sqrt{ }$ & & & & Sering : aspek \\
\hline 3 & $\begin{array}{l}\text { Siswa terlibat aktif } \\
\text { dalam pembelajaran }\end{array}$ & $\sqrt{ }$ & & & & $\begin{array}{l}\text { yang muncul } 2 \\
-3 \text { kali }\end{array}$ \\
\hline 4 & $\begin{array}{l}\text { Siswa terdorong } \\
\text { menggunakan } \\
\text { kemampuannya } \\
\text { untuk berpikir kritis }\end{array}$ & $\sqrt{ }$ & & & & $\begin{array}{l}\text { Jarang : aspek } \\
\text { yang muncul } 1 \\
-2 \text { kali }\end{array}$ \\
\hline 5 & $\begin{array}{l}\text { Siswa dalam belajar } \\
\text { sangat } \\
\text { berantusiasdan } \\
\text { gembira }\end{array}$ & $\sqrt{ }$ & & & & $\begin{array}{l}\text { Tidak pernah: } \\
\text { tidak muncul } \\
\text { sama sekali. }\end{array}$ \\
\hline 6 & $\begin{array}{l}\text { Waktu belajar terjadi } \\
\text { interaksi antara siswa } \\
\text { dengan siswa. }\end{array}$ & $\sqrt{ }$ & & & & \\
\hline 7 & $\begin{array}{l}\text { Terjadi interaksi } \\
\text { siswa dengan guru. }\end{array}$ & $\sqrt{ }$ & & & & \\
\hline 8 & $\begin{array}{l}\text { Siswa mampu } \\
\text { mengeluarkan } \\
\text { pendapat }\end{array}$ & $\sqrt{ }$ & & & & \\
\hline
\end{tabular}

Tabel 4. Hasil Pengamatan Kegiatan guru siklus II

\begin{tabular}{|c|c|c|c|c|c|c|}
\hline \multirow[b]{2}{*}{ No } & \multirow{2}{*}{$\begin{array}{l}\text { Aspek yang } \\
\text { diamati }\end{array}$} & \multicolumn{4}{|c|}{ Hasil pengamatan } & \multirow[b]{2}{*}{ Ket } \\
\hline & & Selalu & Sering & Jarang & $\begin{array}{c}\text { Tidak } \\
\text { pernah }\end{array}$ & \\
\hline $\begin{array}{l}\text { A } \\
1\end{array}$ & $\begin{array}{l}\text { Kegiatan awal } \\
\text { Membangkitkan }\end{array}$ & $V$ & & & & $\begin{array}{l}\text { Selalu : aspek } \\
\text { yang muncul }\end{array}$ \\
\hline
\end{tabular}




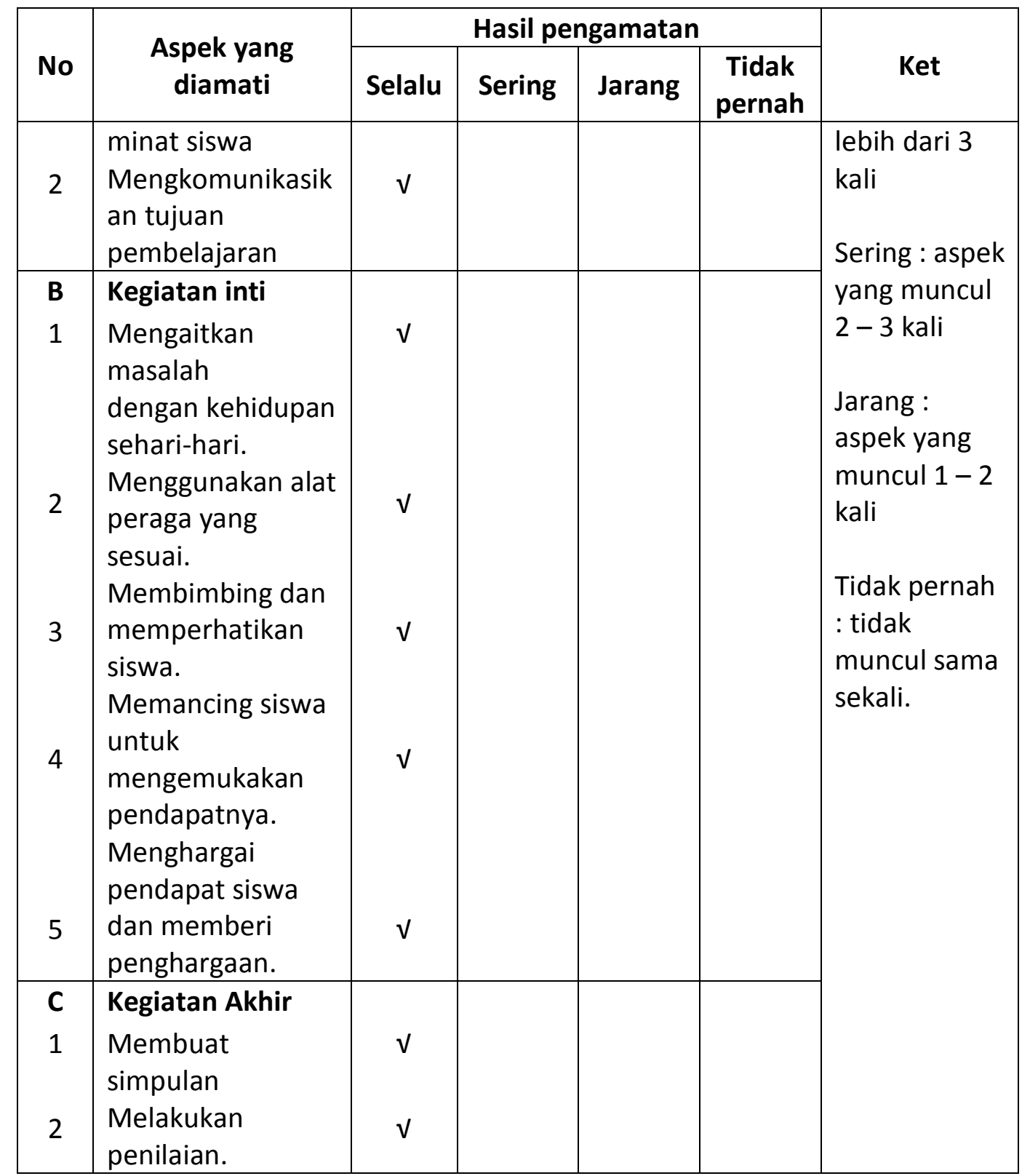

Analisis :

Berdasarkan hasil diskusi dengan teman sejawat, perbaikan pembelajaran siklus II sudah menunjukkan kemajuan. Kemudian dengan menerapkan RPP yang kedua dan menggunakan metode Kooperatif model STAD dapat dilihat hasil belajar siswa mengalami peningkatan menjadi rata-rata $78,60 \%$.

\section{Refleksi}

Pada siklus II dapat dikatakan dengan penyampaian pembelajaran dan pemberian tugas pada siswa mengalami keberhasilan dalam belajar. Pembelajaran berjalan lebih baik sesuai dengan tujuan pembelajaran. 


\section{Pembahasan}

Pada pembelajaran siklus I pengamat mencatat beberapa masalah antara lain :

- Pembelajaran PKN ini masih belum maksimal

- Keaktifan siswa dalam pembelajaran masih kurang

- Interaksi antara siswa dengan siswa atau siswa dengan guru masih jarang terjadi

- Penggunaan alat peraga / metode masih kurang maksimal, guru selalu berceramah terus sehingga siswa seolah-olah hanya sebagai pendengar

- Hasil pembelajaran siklus I ratarata $65,20 \%$

Pada pembelajaran siklus II pengamat mencatat beberapa masalah antara lain :

- Penggunaan PKN sudah berhasil, karena penjelasan disertai dengan penggunaan alat peraga sudah sesuai sehinga anak dapat menerima dan senang

- Kegiatan pembelajaran siswa sudah lebih aktif, karena merasa senang

- Interaksi sesama siswa, guru dengan siswa selalu dilakukan, karena guru selalu membimbing, memperhatikan dan menghargai pendapat siswa

- Penggunaan metode pembelajaran sudah sesuai, siswa berperan aktif dalam setiap kegiatan pembelajaran
- Hasil yang dicapai pada akhir pembelajaran siklus II rata - rata siswa adalah 78,60\%

Berdasarkan kedua siklus yang telah dilaksanakan, peneliti mengamati adanya perubahan yang positif pada setiap siswa pada proses pembelajaran PKN

Adapun perubahan positif tersebut antara lain :

1) Siswa tertarik mengikuti pelajaran

2) Siswa terlihat aktif selama mengikuti pembelajaran

3) Siswa mau mengajukan pertanyaan

4) Siswa ikut aktif ketika membuat simpulan

Hal ini terlihat adanya :

- Antusias siswa dalam mengikuti pembelajaran dari siklus I ke siklus II meningkat

- Hasil yang diperoleh siswa pada akhir pembelajaran dari siklus I ke siklus II meningkat

\section{PENUTUP}

\section{Simpulan}

Berdasarkan kegiatan-kegiatan yang dilakukan dalam Penelitian Tindakan Kelas ini, Peneliti dapat mengambil kesimpulan sebagai berikut:

1. Pembelajaran dengan Metode Koopratif Model STAD memiliki dampak positif dalam meningkatkan prestasi belajar siswa, terutama pada siswa SDN Sedapurklagen Kecamatan Benjeng Kabupaten Gresik, yang ditandai dengan peningkatan 
ketuntasan belajar siswa dalam setiap siklus, yaitu siklus I $(65,20$ \%) Siklus II (78,60 \%).

2. Penerapan Metode Koopratif Model STAD mempunyai pengaruh positif, yaitu dapat meningkatkan motivasi belajar siswa SDN Sedapurklagen Kecamatan Benjeng Kabupaten Gresik, yang ditunjukan dengan rata-rata jawaban siswa yang menyatakan bahwa siswa tertarik dan berminat dengan Metode Koperatif sehingga mereka menjadi termotivasi untuk belajar.

\section{DAFTAR PUSTAKA}

Andayani, Dkk. 2008 Pemantapan Kemampuan Profesional, Jakarta : Universitas Terbuka

Departemen Pendidikan dan Kebudayaan, 1994. Petunjuk Pelaksanaan Proses Belajar Mengajar, Jakarta. Balai Pustaka.

Lie, Anita. 2002. Cooperative Learning. Jakarta : Gramedia.

Margono. $1997 . \quad$ Metodologi Penelitian Pendidikan. Jakarta. Rineksa Cipta.

Poerwodarminto. 1991. Kamus Umum Bahasa Indonesia. Jakarta: Bina Ilmu.

Soekamto, Toeti. 1997. Teori Belajar dan Model Pembelajaran. Jakarta: PAU-PPAI, Universitas Terbuka.

Sudjana, Nana. 2008. Dasar-dasar Proses Belajar Mengajar, Bandung : PT IGAK
Suryosubroto, B. 1997. Proses Belajar Mengajar di Sekolah. Jakarta: PT. Rineksa Cipta.

Wardani, I.G.A.K, Julaecha, Siti, Marsinah, Ngadi. 2007. Panduan Pemantapan Kemampuan Profesioanal, Jakarta : Universitas Terbuka

Wardhani, dkk. 2007. Karya Tulis Ilmiah. Jakarta : Universitas Terbuka

Wena, Made. 2009. Strategi Pembelajaran Inovatif Kontemporer. Jakarta : Bumi Aksara

Wetherington. H.C. dan W.H. Walt. Burton. 1986. Teknik-teknik Belajar dan Mengajar. (terjemahan) Bandung: Jemmars.

Winataputra, Udin S, dkk. 2007. Teori Belajar dan Pembelajaran, Jakarta : Universitas Terbuka. 